\title{
A SIMULATION APPROACH TO FACILITATE MANUFACTURING SYSTEM DESIGN
}

\author{
Fandiño Pita, J. \& Wang, Q. \\ School of Engineering and Computing Sciences, Durham University, Durham, DH1 3LE, U.K. \\ E-Mail: javier.fandino@ymail.com, qing.wang@durham.ac.uk
}

\begin{abstract}
In recent years, the manufacturing sector has faced unparalleled levels of change and its intricacies are also challenging. This has lead to manufacturers acquiring new methods for planning and control of their manufacturing systems. One approach that can give good results in this context is simulation modelling. In this paper, a simulation modelling technique is applied to a bottling process in a winery to analyze the variations in the duration of the process with different changes in the production line. Step changes have been made during the simulation model construction. Based on the results of this study, it is possible to predict in which parts of the process it is best to invest so that a greater yield can be obtained. The objective of this study was achieved, since the process duration could be reduced from a twoday bottling process to attain all the bottling in a single day.

(Received in January 2010, accepted in May 2010. This paper was with the authors 2 months for 1 revision.)
\end{abstract}

Key Words: Manufacturing Systems Design, Simulation Modelling, Process Optimisation

\section{INTRODUCTION}

In the last few years, manufacturing companies have been competing in an increasingly dynamic environment. Among them, Small and Medium-sized businesses are increasing considerably, innovations are on the rise and product-life cycles are getting shorter. For this reason, companies need to devote more effort and resources in order to be able to compete in a highly competitive market and to continue to generate profit, as this is increasingly necessary to reduce the cost of production.

Despite availability of different tools and techniques proposed for manufacturing industry, it has been reported that manufacturers are usually facing significant practical problems when trying to model in detail the way they operate [1] or to implement changes in existing environments. A very useful tool that helps avoid unnecessary expenses and also gives an idea of the possible effectiveness of systems in advance is simulation. According to Bennett [2], simulation can be defined as "a technique or a set of techniques whereby the development of models helps one to understand the behaviour of a system, real or hypothetical”. For this reason, simulation is widely associated with exploring possibilities for evaluating system behaviour by applying internal/external changes and for supporting process enhancement efficiency and organization [3].

Simulation has numerous other benefits, for example: manufacturing processes can be analyzed without interrupting the real system, to avoid investing the high cost of implementing a system, to enable training and to make learning possible, to check if the analytic solutions offered by the analysis of mathematical models are correct, to answer questions about how or why the phenomena occur, or to know how a small change in a part of the system affects the whole manufacturing system [4].

Because of these uses of simulation, if a good simulation is carried out, it can improve effectiveness in production. This is a key competitive advantage for the company, since 
planning and implementation of production is becoming strategically important within companies and may cause the business to acquire a competitive advantage. Information provided by the simulation models are based on input data. Therefore, it is very important that the variables are analyzed properly and that input data are reliable. In the same way, a comprehensive knowledge of statistics is necessary to interpret output data correctly.

\section{SIMULATION APPLICATIONS}

There are many areas where simulation is used and they are still increasing. Manufacturing has traditionally been one of the most important areas for the application of simulation. The state of the art literature review reports several studies in the field. Chisman [5] constructed a simulation model to study and modify material flow operations. The model was then employed to assist the investigation of daily and weekly schedules. Chan and Smith [6] developed a simulation model using GPSS/H to evaluate the performance of a welding assembly in a car factory. Morito and Lee [7] focus on short period production planning problems. They use simulation to study the dispatching rule optimization with random process time. Dweiri and Meier [8] also investigated the application of fuzzy sets theory in facilities layout planning. Longo et al. [9] performed material flow analysis and used a simulation approach to optimize the plant lay-out of a manufacturing system. Madu [10] proposed a framework to analyse maintenance float problems by using regression metamodels in post simulation analysis to solve important decision making problems. Chan and Chan [11] presented a case study of a PCB factory by using simulation analysis. In their paper, the simulation analysis of a serial production line was carried out. The full factorial design was implemented as a simulation analysis tool to obtain the optimal output.

In a survey that Abu-Taieh and Sheikh [12] performed in 2007, they studied 56 simulation packages with specific features for modelling in certain simulation applications. The results showed that $14 \%$ of the 56 simulation packages studied have features which easily model resources or characteristics of manufacturing systems, such as the increase in machinery and resource utilization, the reduction in the average time in the system, and/or improvement in the performance of the system, as well as to ensure that the behaviour of the system is in line with what is expected. In addition, all of the information necessary to build the model allows the manager or engineer to better understand the system.

According to Law and Kelton [13] the features that can be obtained and the issues that can be analyzed are divided into three general categories:

- The need for and quantity of equipment and personnel.

- Performance evaluation.

- Evaluation of operational procedure.

Apart from manufacturing applications, simulation techniques have been widely used in other areas. For example, de Freitas Filho et al [14] used simulation to predict market behaviour for outbound call centres. Similar to this, Al-Shorman \& Jbara [15] in their paper describe how simulation was constructed for business case benefits and return on investment for the procurement of eight production machines. Kuljis, Paul \& Stergioulas examine the potential use of simulation modelling in health care and discuss seven axes of differentiation [16]. McGarvey et al [17] present a discrete event model of the patient enrolment process during clinical trials. Chapman et al [18] developed a high-fidelity simulation test bed for various network architectures for communication between components of tactical unmanned aerial systems. 


\section{PROBLEM FORMULATION}

This paper discusses a case study that has been constructed to simulate a bottling plant of a winery in San Martiño de Meis in the province of Pontevedra, Spain. At present, the winery produces 360,000 litres of white wine a year marketed under two products. Their main product is Mar de Frades, and the other product, Algareiro, is produced for export. Both are the same wine, the only difference is the type of bottle, and the product under which they are marketed.

The method of production employed by the company depends on demand, but the minimum amount they can produce at any given time is 10,000 litres, which is equivalent to the storage capacity of each of their wine tanks. The problem is that the bottling process takes two days to complete and it would be in the interest of the winery if they were able to do so in only one day, for the following reasons:

- Wine left in a tank starts to oxidize and for this reason wine left to stand for one day to the next loses quality considerably.

- Whenever the machinery is to be used, as well as after the production process, the filters and all of the channels along which the wine passes have to be sterilized, Therefore, if bottling is a two-day operation, it is a process which must be repeated up to four times, instead of twice, which would be the case if bottling could be done in only one day.

- Any starting and stopping of the machinery implies a loss of energy and time until the system is properly up and functioning.

Due to the disadvantages of a two-day bottling process the company is considering an investment to improve the line of production for bottling so as to be able to bottle the 10,000 litres of wine in a single day. Therefore, the main purpose of this study is to employ simulation as a tool to analyse ahead of time the possible effectiveness of such a system. Through the simulation analysis, the following performance measure will be investigated: whether or not an investment of this type would be worthwhile and where the improvement is needed to improve the quality of the bottled wine, as well as to be better able to employ the workforce in other areas, with the corresponding economic saving this would represent.

\section{THE REAL MODEL}

\subsection{Conceptual model}

The conceptual model as shown in Fig. 1 has been developed to present the layout of the bottling process.

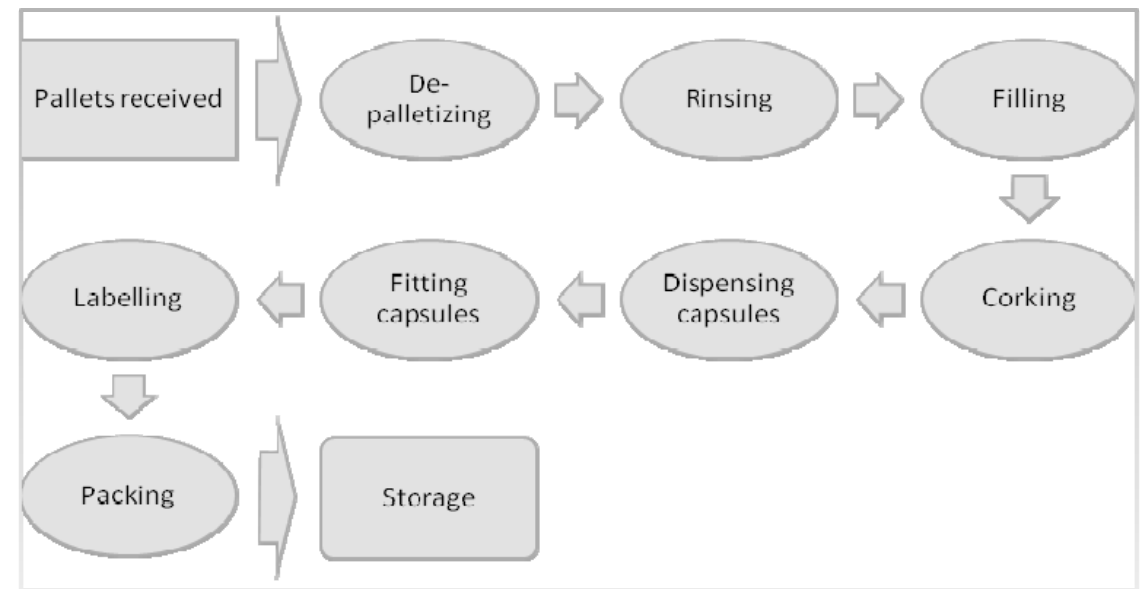

Figure 1: Conceptual model of bottling process. 
The production line consists of different types of production work centres. They include a de-palletizing machine, a tri-bloc wine bottling machine (a rinsing machine, a filler machine, and a corking machine), a capsules dispenser machine, a capsules fitter machine, a label machine and finally a packing machine. The existing facilities of the winery are presented in Table I.

Table I: Winery facilities of various work centres.

\begin{tabular}{|l|l|c|}
\hline Work centre & Machine function & $\begin{array}{c}\text { Machine } \\
\text { head }\end{array}$ \\
\hline $\begin{array}{l}\text { De-palletizing } \\
\text { machine }\end{array}$ & $\begin{array}{l}\text { Collect the bottles and place } \\
\text { them on various conveyor belts }\end{array}$ & 1 \\
\hline Rinsing machine & Rinse the bottles & 9 \\
\hline Filler machine & Bottles are filled with wine & 9 \\
\hline Corking machine & The bottle is corked & 1 \\
\hline $\begin{array}{l}\text { Capsules dispenser } \\
\text { machine }\end{array}$ & $\begin{array}{l}\text { Puts the capsules on each bottle } \\
\text { without shrinking or wrapping }\end{array}$ & 4 \\
\hline $\begin{array}{l}\text { Capsules fitting } \\
\text { machine }\end{array}$ & $\begin{array}{l}\text { Capsule properly fitted around its } \\
\text { neck. }\end{array}$ & 4 \\
\hline Labelling machine & Stick the labels around the bottle & 1 \\
\hline Packing machine & $\begin{array}{l}\text { Bottles have been packed and } \\
\text { ready to be put into the storage }\end{array}$ \\
\hline
\end{tabular}

The bottling process starts when empty bottles are transported from the warehouse to the de-palletizing machine, which collects the bottles by means of an air-compression system which places them on various conveyor belts. These bottles are moved along to a tri-bloc hub made up of a rinsing machine, a filler machine and a corking machine. A rotation system is employed in which the machine incorporates a bottle for rinsing and after being passed around the rinsing hub, the bottle is returned to the conveyor belt from where it immediately passes to the filling machine, in which the same rotation process is employed. This method is not employed at the corking process stage. The plugging or corking machine only has one head and until each bottle is corked the machine can not start on the next bottle waiting in line.

The next machine along the conveyor belt is the capsule machine which places the capsules around the corks and necks of the bottles. The bottles, with their corks plugged and capsules fitted, continue to move along the conveyor belt until they reach the labelling machine. In here, each bottle is stickered with four labels. When the bottles leave the labelling machine, they reach the end of the conveyor belt, and the bottles are packed and moved to a small storage area ready for dispatch from the winery.

\subsection{Assumptions}

To ensure the model represents the real system as closely as possible, several assumptions have been taken into account during the development of the simulation model as follows:

- There are unlimited arrivals at the work entry point, in this way the system always has sufficient bottles.

- The conveyors will stop completely when a bottle reaches the front of the queue to maintain the correct spacing between bottles. 
- For rinsing and filling, nine bottles can be processed at the same time, as the nine heads are independent of each other. Similar assumptions have been made to capsule fitting and the labelling machine; they have four heads instead of nine.

- It has been estimated that $1 \%$ of bottles processed by the capsule-fitted machine have to be "re-capsulated" and $0.5 \%$ of bottles that go through the labelling machine have to be re-labelled.

- The winery bottles 10,000 litres with each bottling process, in which $75 \%$ of total produced bottles are labelled Mar de Frades and the rest are labelled as Algareiro.

- The de-palletizing machine requires 75 minutes for changeover to alter the height of the machines, change the supports of the machines and also change the types of corks, capsules and labels.

- "Seconds" have been chosen as the means of measurement for simulation time. The simulation time has been set up for 2 days as the production line takes 2 days to bottle a 10,000-litre tank. Four operators are necessary to work in the line.

\section{SIMULATION MODELLING AND VALIDATION}

\subsection{Building the simulation model}

Having analysed all the stages in the wine manufacturing process a simulation model has been generated using Simul8 [19]. The screenshot of the model is presented in Fig. 2. The numerical results and animation have been reviewed carefully and investigations are carried out to analyse the process time for each machine and identify the relationships between input variables and output variables.

The proposed time distributions of each operation are presented in Table II. For each operation 50 samples of processing time have been measured. From the samples of processing time obtained, it is necessary to know what distribution the data fits. Most of them could fit a parametric or pre-defined distribution, but an empiric distribution had to be created in Simul8 for the processing times of corking and packing machine.

Table II: Time distribution and related parameters for each machine.

\begin{tabular}{|l|l|c|}
\hline Work centre & Distribution & Parameters \\
\hline De-Palletizing machine & Uniform & 10,20 \\
\hline Rinsing machine & Normal & $38.7,1.9$ \\
\hline Filler machine & Normal & $37.2,1.8$ \\
\hline Corking machine & Defined by Simul8 & \\
\hline Capsules dispenser machine & Fixed & 1 \\
\hline Capsules fitting machine & Normal & $14.3,2.1$ \\
\hline Labelling machine & Normal & $13.6,1.9$ \\
\hline Packing machine & Defined by Simul8 & \\
\hline
\end{tabular}

A discrete probability profile of the corking machine with 8 columns will be built in Simul8. Each column will contain the percentage of all measured data which is within the corresponding interval. The frequency and percentage are shown in Table III. 
Table III: Data for profile distribution of corking.

\begin{tabular}{|c|c|c|c|}
\hline Columns & Bin & Frequency & Percentage \\
\hline 1 & $(4.1,4.2)$ & 2 & $4 \%$ \\
\hline 2 & $(4.2,4.3)$ & 12 & $24 \%$ \\
\hline 3 & $(4.3,4.4)$ & 1 & $2 \%$ \\
\hline 4 & $(4.4,4.5)$ & 13 & $26 \%$ \\
\hline 5 & $(4.5,4.6)$ & 8 & $16 \%$ \\
\hline 6 & $(4.6,4.7)$ & 5 & $10 \%$ \\
\hline 7 & $(4.7,4.8)$ & 9 & $18 \%$ \\
\hline 8 & $(4.8, \infty)$ & 0 & $0 \%$ \\
\hline
\end{tabular}

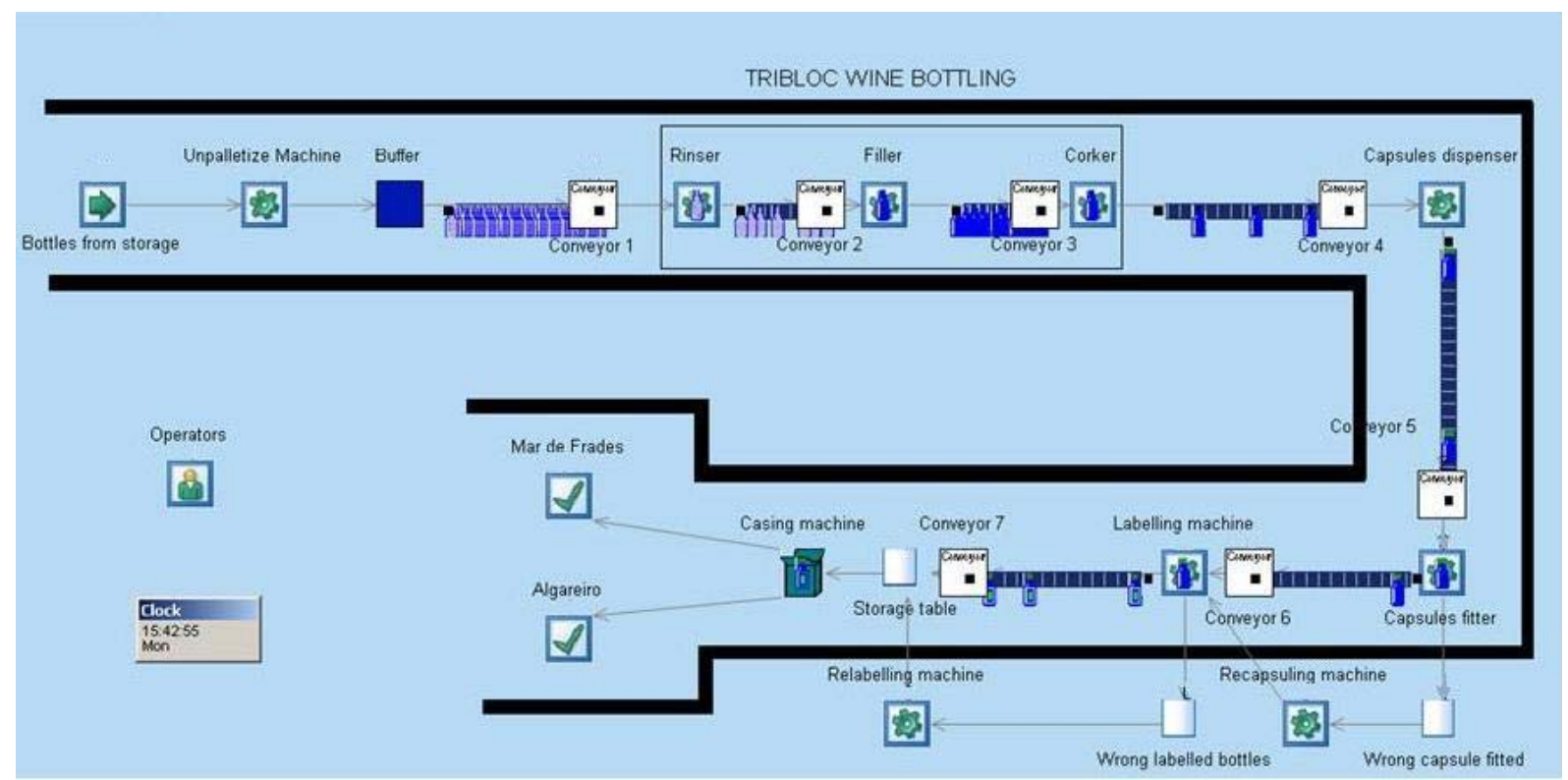

Figure 2: Simulation model of wine bottling process.

Every bottle is moved from one work centre to another along conveyors. The maximum number of bottles that can be held on a conveyor is managed by the diameter of bottle and the length of the conveyor. This data have been measured directly and are shown in Table IV. The other parameter of conveyors is the speed, which is used to calculate the amount of time required to move items along the conveyor. In this model, all the conveyors have the same speed, which is equal to 14.5 metres per minute.

Table IV: Data measured in conveyors.

\begin{tabular}{|l|c|}
\hline \multirow{2}{*}{ Diameter of bottle } & Mar de Frades: 7 cm \\
\cline { 2 - 2 } & Algareiro: $6.3 \mathrm{~cm}$ \\
\hline Conveyor 1 (from buffer to rinser) & $3.3 \mathrm{~m}$ \\
\hline Conveyor 2 (from rinser to filler) & $0.7 \mathrm{~m}$ \\
\hline Conveyor 3 (from filler to corker) & $0.7 \mathrm{~m}$ \\
\hline Conveyor 4 (from corker to capsules dispenser) & $3.7 \mathrm{~m}$ \\
\hline Conveyor 5 (from dispenser to capsules fitter) & $1.5 \mathrm{~m}$ \\
\hline Conveyor 6 (from fitter to labelling) & $1.6 \mathrm{~m}$ \\
\hline Conveyor 7 (from labelling to packing) & $1.5 \mathrm{~m}$ \\
\hline
\end{tabular}




\subsection{Validating the simulation model}

To validate the data, several results have been compared with measured data and a set of input and output variables have been chosen. The selected input variables are: conveyor speed, process time of all machines, rejection rate of wrong capsule-fitted bottles and rejection rate of wrongly labelled bottles. The output variables are: duration of the process, cycle time of the system, percentage of the working time spent by each machine, percentage of waiting time and percentage of blockage time.

The validation method developed for this case study is based on Olmos et al's work [20] which classifies the input variables as a function of how they affect output variables. In this way, the most influential variables have been presented and modified in order to increase the performance of the system. Defining $\mathrm{X}$ as the input variable and $\mathrm{Y}$ as the output variable, the input variable will be classified in the following way:

- Absolutely critical: if any change in the input variable, both rise and reduction, involves a variation in the output variable:

$$
\begin{aligned}
& \Delta X>0=\Delta Y \neq 0 \\
& \Delta X<0 \Rightarrow \Delta Y \neq 0
\end{aligned}
$$

- Critical: if a rise in the input variable modifies the output variable and, however, a reduction in the same variable does not, or vice versa:

$$
\left.\begin{array}{l}
\Delta X>0 \Rightarrow \Delta Y \neq 0 \\
\Delta X<0 \Rightarrow \Delta Y=0
\end{array}\right\} \quad \text { Or if } \quad\left\{\begin{array}{l}
\Delta X>0=\Delta Y=0 \\
\Delta X<0=\Delta Y \neq 0
\end{array}\right.
$$

- Insensitive: if any change in the input variable does not involve any modification in the output variable:

$$
\forall \Delta X \neq 0 \Rightarrow \Delta Y=0
$$

Once the absolutely critical variables are determined, the study focuses on the variables with longer sensibility. These input variables produce a big change in the output variable with a small modification in itself:

$$
\text { Sensibility }_{X Y}=\frac{\Delta Y}{\Delta X}
$$

To analyse the input data, eight input variables have been selected. They have been compared with all the output data chosen in the real model with the same output data once one input variable is modified. These have been done with all the input data chosen, one by one. Table V shows the current and proposed facility settings to be modified in the existing winery. Using conveyors speed as an example, the results can be seen in Table VI and the arrows show if the output has changed. The arrows included in the cells have the following meaning:
$\Rightarrow$ : The value is in an interval between the real model's value $\pm 1 \%$.
仓: The value is larger than the real model's value $+1 \%$.
$\S$ : The value is smaller than the real's value $-1 \%$. 
Table V: The value of current and proposed input variables.

\begin{tabular}{|l|c|c|c|}
\hline Input variable & Current parameter & $\begin{array}{c}\text { Proposed } \\
\text { parameter 1 }\end{array}$ & $\begin{array}{c}\text { Proposed } \\
\text { parameter 2 }\end{array}$ \\
\hline Conveyors speed & 0.2 & 0.5 & 0.1 \\
\hline Process time of rinsing machine & 38.7 & 70.0 & 18.0 \\
\hline Process time of filling machine & 37.2 & 70.0 & 18.0 \\
\hline Processing time of corking machine & 4.0 & 8.0 & 2.0 \\
\hline Processing time of capsule fitter machine & 14.3 & 28.0 & 7.0 \\
\hline Processing time of labelling machine & 13.6 & 28.0 & 8.0 \\
\hline Processing time of packing machine & 45.0 & 90.0 & 23.0 \\
\hline Rejection rate of wrongly labelled bottles & $1 \%$ & $5 \%$ & $0 \%$ \\
\hline Rejection rate of wrongly fitted bottles & $1 \%$ & $5 \%$ & $0 \%$ \\
\hline
\end{tabular}

Table VI: Analysis of conveyor speed.

\begin{tabular}{|c|c|c|c|c|c|}
\hline Output variable & $\begin{array}{c}\text { Real model } \\
(0.2)\end{array}$ & $\begin{array}{r}\text { Conveyo } \\
(0.5\end{array}$ & speed & $\begin{array}{r}\text { Conveyo } \\
(0.1\end{array}$ & peed \\
\hline Duration (s) & 63061 & 63026 & $\Rightarrow$ & 63186 & $\Rightarrow$ \\
\hline Cycle time Mar de Frades & 1538.8 & 1518.8 & 及 & 1584.8 & î \\
\hline Cycle time Algareiro & 1837.7 & 1809.0 & 凸 & 1887.8 & 仓े \\
\hline \% Working rinser & 91.2 & 91.2 & $\Rightarrow$ & 91.1 & $\Rightarrow$ \\
\hline$\%$ Awaiting rinser & 5.9 & 5.9 & $\Rightarrow$ & 6.0 & $\Rightarrow$ \\
\hline \% Blocked rinser & 2.7 & 2.7 & $\Rightarrow$ & 2.8 & iि \\
\hline \% Working filler & 87.7 & 87.6 & $\Rightarrow$ & 87.5 & $\Rightarrow$ \\
\hline$\%$ Awaiting filler & 6.0 & 5.9 & $\Rightarrow$ & 6.1 & $\widehat{\imath}$ \\
\hline \% Blocked filler & 6.2 & 6.3 & $\hat{\imath}$ & 6.3 & $\Rightarrow$ \\
\hline \% Working corker & 93.8 & 93.8 & $\Rightarrow$ & 93.7 & $\Rightarrow$ \\
\hline \% Awaiting corker & 5.9 & 5.9 & $\Rightarrow$ & 6.0 & 仓े \\
\hline \% Blocked corker & 0 & 0 & $\Rightarrow$ & 0 & $\Rightarrow$ \\
\hline \% Working capsule fitter & 75.7 & 75.7 & $\Rightarrow$ & 75.6 & $\Rightarrow$ \\
\hline \% Awaiting capsule fitter & 24.1 & 24.1 & $\Rightarrow$ & 24.1 & $\Rightarrow$ \\
\hline \% Blocked capsule fitter & 0.04 & 0.01 & $\S$ & 0.21 & $\hat{\imath}$ \\
\hline \% Working labeller & 71.7 & 71.7 & $\Rightarrow$ & 71.6 & $\Rightarrow$ \\
\hline \% Awaiting labeller & 28.2 & 28.2 & $\Rightarrow$ & 28.1 & $\Rightarrow$ \\
\hline \% Blocked labeller & 0.02 & 0.005 & $\S$ & 0.1 & $\hat{\imath}$ \\
\hline \% Working casing & 93.8 & 93.8 & $\Rightarrow$ & 93.7 & $\Rightarrow$ \\
\hline$\%$ Awaiting casing & 5.9 & 5.9 & $\Rightarrow$ & 6.0 & $\Rightarrow$ \\
\hline
\end{tabular}

Several observations have been made directly from these experiments:

1. The results show that conveyor speed is almost insensitive to the majority of the other variables and, if not entirely insensitive, has little sensibility. Therefore, conveyor speed is not a very important variable to modify the model. 
2. The processing time of the corking machine is an absolutely critical input variable for all the output data due to the fact that all of them have changed. It seems clear that it is better to reduce this process time because such changes would reduce the duration of the process, the cycle time and the percentage of working time in almost all the machines.

3. The process time of the other machines are critical variables with regard to the output data, but not absolutely critical. In general, if the process time is reduced, most of the output data would not be modified. By increasing the process time, the output date would change, but the results would be worse, as witnessed by the resulting doubling in the duration of the process.

4. Both the rejection rate of wrong capsule-fitted bottles and the rate of wrongly labelled bottles are insensitive to most of the output variables, neither by rising nor by reducing this rate do they change. Thus they are not analysed in the optimization of the real model.

To investigate further, after 5 replicates with the model, the $95 \%$ confidence interval for the duration of the process is between 63065.53 seconds and 63109.47 seconds with a mean of 63087 seconds. This means that the process would finish at 16:31 on the second day with a $95 \%$ confidence if there is a 9-hour working day and they finish the process the second day. The simulation results tally with the process duration declared by the operators. When looking at the cycle time, the average cycle time that a bottle of wine spends in the system before reaching the work exit point is in an interval between 1538.12 and 1539.54 seconds and the mean is 1538.83 seconds. The results show that most of the bottles have a cycle time between 1150 and 1910 seconds and this matches the data collected from the real system. During the time when the data is being measured, the maximum number of bottles that can be held on the storage table is 12 . The simulation model provides a maximum queue size of 13 bottles and an average queue size of 3.69 bottles. These results confirm that the simulation result matches the measured data from the real system and that the model behaves like the real system. It is therefore considered that the model is validated.

\section{ALTERNATIVE PROPOSAL TO IMPROVE THE SYSTEM}

As mentioned earlier, the simulation model should be used for carrying out specific what-if analysis and it was possible to try to improve the system with the changes necessary to achieve the goal which enables the completion of the bottling process of 10,000 litres of wine in a single day. To this end, this study is supported by modifications of selected input variables. Seven different scenarios have been created with the following new input variables:

- Scenario 1: Two corking machines

- Scenario 2: Number of rinsing machines increased by $100 \%$

- Scenario 3: Number of filling machine increased by $100 \%$

- Scenario 4: Process time of packing machine reduced

- Scenario 5: Number of capsule fitting machine increased by $100 \%$

- Scenario 6: Number of the labelling machine increased by $100 \%$

- Scenario 7: Three corking machines and one more operator.

The initial cost to set up the bottling process will be €36,547.93. Careful plans have to be put in palace if the above seven changes are to be made to the systems. The estimated cost of a new Tri-bloc machine will be $€ 150,000$. This would be the investment to make the change in scenarios 1, 2 and 3. For scenario 5, a new capsule fitting machine will need to be put in at 
a cost of $€ 60,000$ and for scenario 6, a new labelling machine, we would need $€ 80,000$. Scenario 4 does not need extra investment; but requires a better organisation of the operators. Scenario 7 would cost the wage of a new operator at $€ 10$ per hour, although this is not an investment, this would incur extra expense. The simulation results of each scenario were observed and stored for analysis. These analyses of the variation of the output variables are presented in the following sub-sections.

\subsection{Duration of the process}

Fig. 3 demonstrates the simulation results in terms of the investigation of the shortest process duration. From the simulation result analysis, scenario 7 is the best option, characterized by a process time of 32,142 seconds. Due to the fact that the goal of producing all the bottles in a single day has been reached, the model will not be improved further.

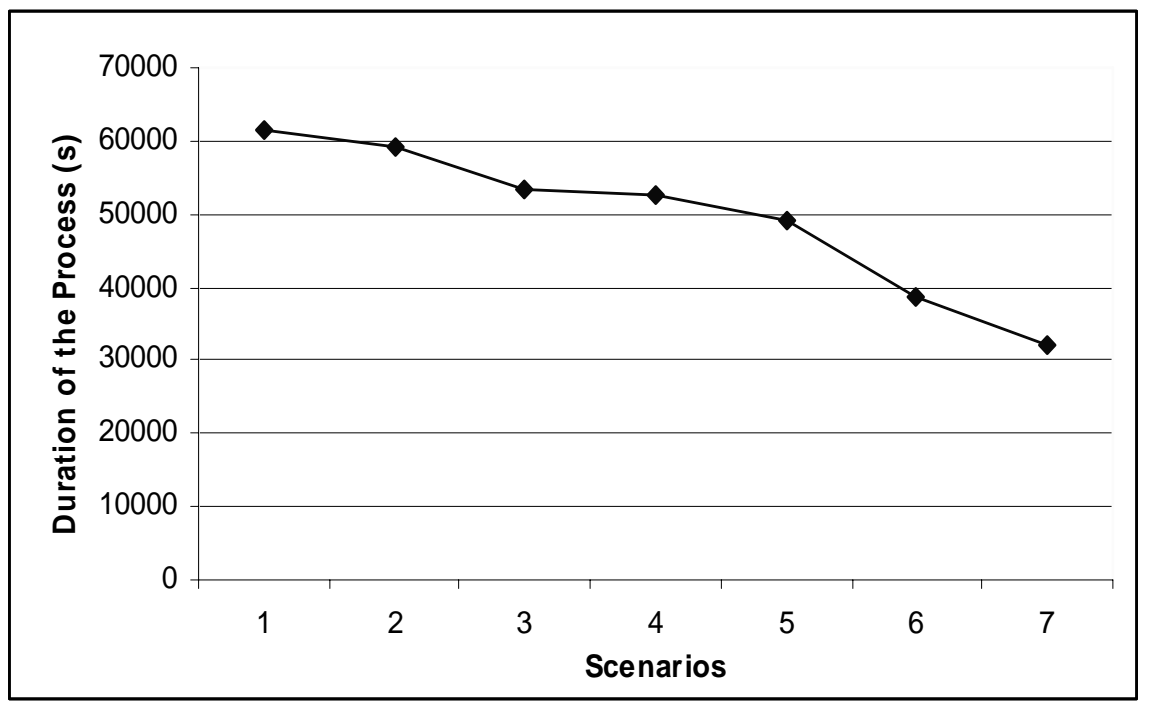

Figure 3: Changes in the process time over 7 scenarios.

\subsection{Percentage of utilization of the machines}

Regarding the utilization of the machines, the results obtained in the simulation show that the percentage of working in each machine is reduced in the scenario where the number of heads of this machine is increased, since the processing time is reduced. Scenario 7 is analysed in depth due to the fact that it is the only one capable of producing all the bottles in a single day. Fig. 4 shows that the percentage of working time for all machines is high enough, including scenario 7. The percentage of blocked time of every machine is quite high in some scenarios because the process time of the previous machine has been reduced. Therefore, such scenarios cannot be considered valid due to the fact that it has a bottleneck in one machine (for example, corking machine is a bottleneck in scenario 3, because it has $37 \%$ of blocked time). However, the blocked time of all machines is virtually nil in scenario 7, this means this scenario is absolutely valid.

Regarding the percentage of awaiting time in scenario 7, these data are acceptable, although the $30 \%$ of awaiting time in the corking machine is a little high. This means that the corking machine has a buffer and the system is prepared to be extended, in case of further necessity, without having to extend the capacity of the corking machine. 


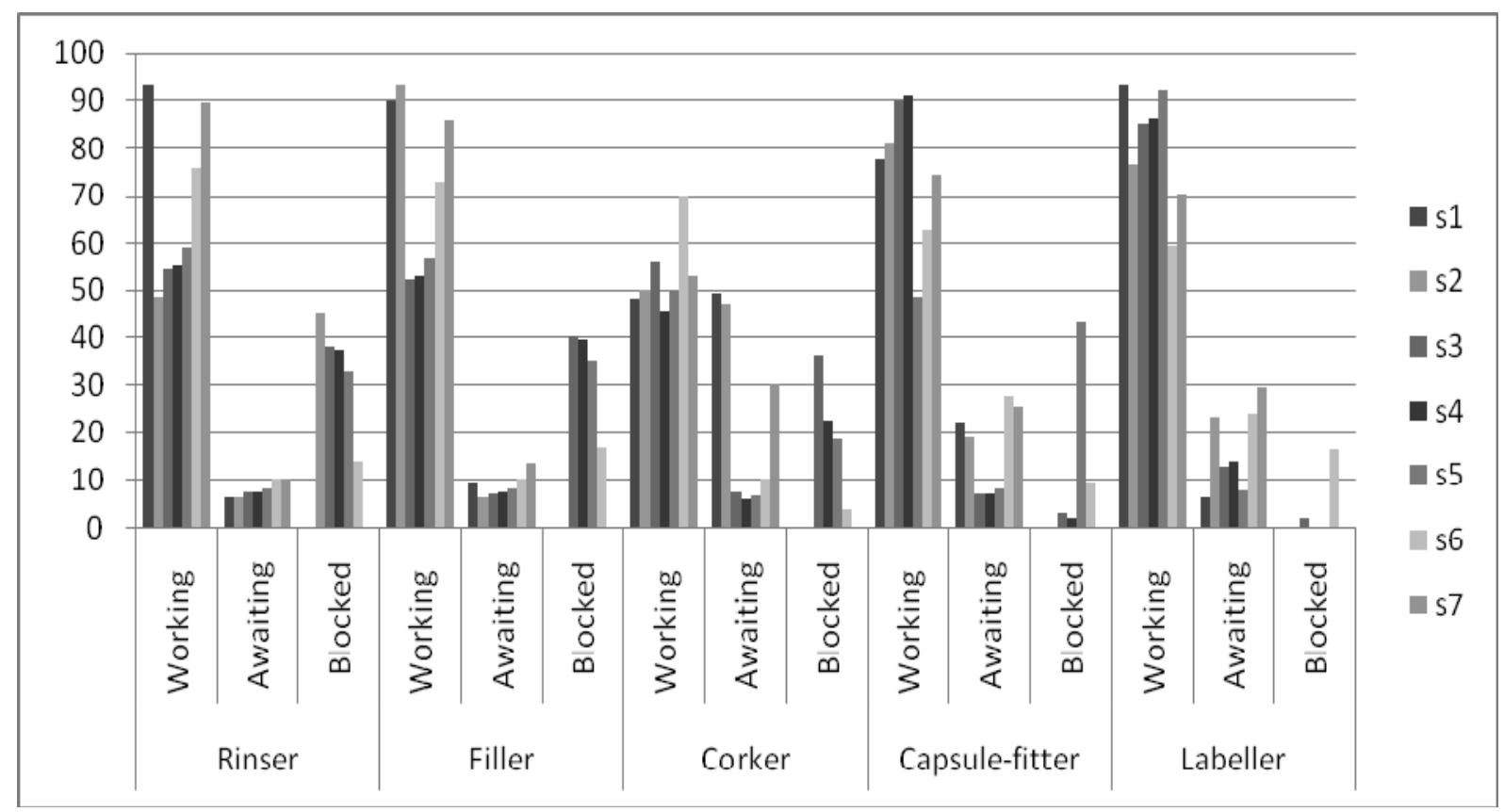

Figure 4: Percentage of utilization of each machine in all scenarios.

It is important to keep in mind that the four operators belonging to the system have a utilization of $68 \%$ in scenario 3. Therefore, scenario 4 required a re-organization of the operators. This way, up to 4 operators can be working in the packing machine if they were available. With this, the percentage of utilization of the operators is $94 \%$ in scenario 4 . One more operator was added in scenario 7 (5 operator in the system) and this scenario attained $94.67 \%$ and this means that all operators are fully utilized.

\subsection{Cycle time of a bottle}

Analysing the output variable cycle time (seconds spent by a bottle in the system), Fig. 5 shows that the cycle time is reduced in the last scenarios, when the duration of the overall process is also reduced. There is an exception in scenario 3 , due to the fact that the rinsing, filling and corking machines have a high percentage of blocked time and the bottles spend too much time in the queues, and therefore in the system.

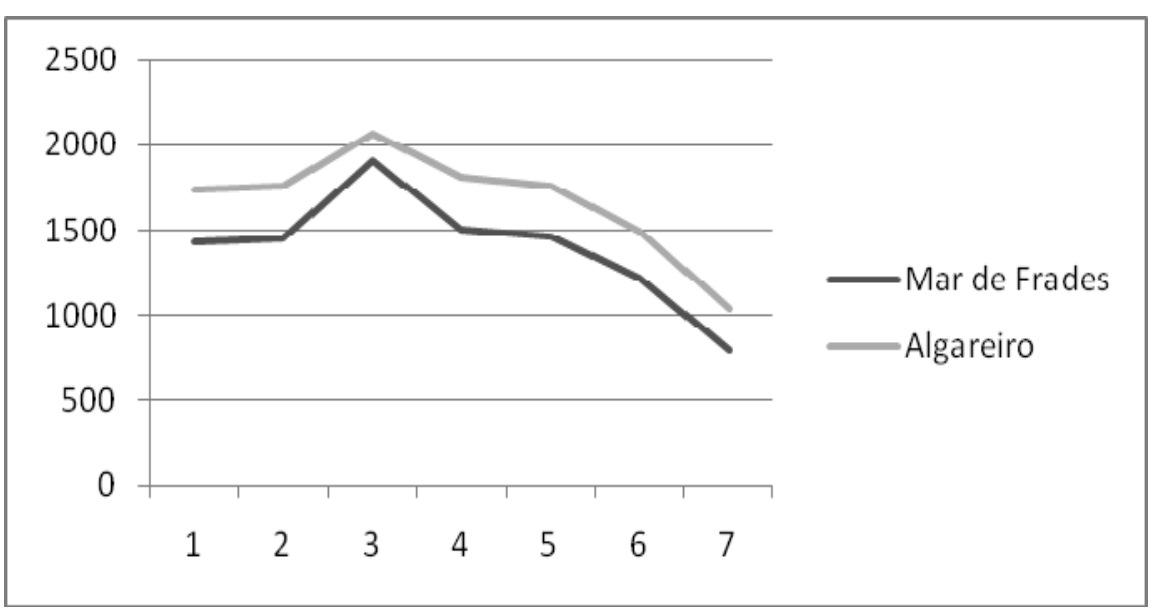

Figure 5: Changes in the cycle time over 7 scenarios. 
Due to the fact that the goal of producing all the bottles in a single day has been reached in scenario 7, and the ratios of utilization of all machines are positive, as well as the utilization of the operators and the cycle time of the bottles, the real system could be improved with the modifications applied from the model of scenario 7.

\section{CONCLUSION}

Simulation has been used for many years to investigate the process and operations for manufacturing sectors. The discrete event modelling approach performs better than the traditional library-based approach in terms of model flexibility, model capability and resources required to execute a simulation run. In this paper, simulation modelling is applied to a bottling process in a winery to analyse the variation in the duration of the process in presence of different changes in the production line. The simulation model validation shows the capability of the simulation model to recreate, with satisfactory accuracy, the real system. This objective was successfully achieved through the improvements performed step by step in a simulation model created by means of Simul8. This model and its modifications proved that it is possible, but also showed that some changes in the machinery and in the distribution of resources were essential.

\section{REFERENCES}

[1] Hansen, L. P.; Jagannathan, R. (1994). Accessing specification errors in stochastic discount factor models, Journal of Finance, Vol. 52, No. 2, 557-590

[2] Bennett, B. S. (1995). Simulation fundamentals, Prentice Hall International, Hertfordshire

[3] Bruzzone, A. G.; Brandolini, M.; Longo, F. (2006). Enhancement process based on simulation supporting efficiency \& organization, Simulation Series, Vol. 38, Part 4, 393-398

[4] Banks, J.; Carson, J. S.; Nelson, B.; Nicol, D. (2005). Discrete-event system simulation, Prentice Hall International, New York

[5] Chisman, J. A. (1989) Apple uses simulation to improve PCB/FMS line design and operation, Industrial Engineering, Vol. 21, No. 7, 40-41

[6] Chan, F. T. S.; Smith, A. (1993) Simulation approach to assembly line modification: a case study, Journal of Manufacturing Systems, Vol. 12, No. 3, 239-245

[7] Morito, S.; Lee, K. H. (1997) Efficient simulation/optimization of dispatching priority with "fake" processing time, Proceedings of the $29^{\text {th }}$ Winter Simulation Conference, 872-879

[8] Dweiri, F.; Meier, F. A. (1996). Application of fuzzy decision-making in facilities layout planning, International Journal of Production Research, Vol. 34, No. 11, 3207-3225, doi:10.1080/00207549608905085

[9] Longo, F.; Mirabelli, G.; Papoff, E. (2005). Material flow analysis and plant layout optimisation of a manufacturing system, International Journal of Computing, Vol. 5, No. 1, 107-116

[10] Madu, C. N.; Kuei, C.-H. (1993). Simulation analyses of a maintenance float shop, International Journal of Production Economics, Vol. 29, No. 2, 149-157

[11] Chan, F. T. S.; Chan, H. K. (2003). Simulation analysis of a PCB factory using factorial design a case study, International Journal of Advanced Manufacturing Technology, Vol. 21, No. 7, 523533

[12] Abu-Taieh, E.; El Sheikh, A. (2007) Commercial simulation packages: a comparative study, International Journal of Simulation, Vol. 8, No. 2, 66-76

[13] Law, A. M.; Kelton, W. (2007). Simulation Modeling and Analysis, McGraw-Hill, Singapur

[14] de Freitas Filho, P. J.; Ferreira da Cruz, G.; Seaea, R.; Steinmann, G. (2007). Using simulation to predict market behavior for outbound call centers, Proceedings of the $39^{\text {th }}$ Winter Simulation Conference, 2247-2251

[15] Al-Shorman, H.; Jbara, Y. H. (2007). Investment prediction using simulation, World Academy of Science, Engineering and Technology, Vol. 33, 180-182 
[16] Kuljis, J.; Paul, R. J.; Stergioulas, L. K. (2007). Can health care benefit from modelling and simulation methods in the same way as business and manufacturing has?, Proceedings of the $39^{\text {th }}$ Winter Simulation Conference, 1449-1453

[17] McGarvey, B. M.; Dynes, N. J.; Lin, B. C.; Anderson, W. H.; Kremidas, J. P.; Felli, J. C. (2007). A discrete event model of clinical trial enrolment at Eli Lilly and company, Proceedings of the $39^{\text {th }}$ Winter Simulation Conference, 1467-1474

[18] Chapman, R.; Hamilton, D.; Box, D.; Kuhr, M.; MacDonald, J.; Hamilton, S. (2007). Simulation of army unmanned aerial vehicle communications, Proceedings of the $39^{\text {th }}$ Winter Simulation Conference, 1324-1327

[19] Hauge, J.; Paige, K. (2001). Learning Simul8, the Complete Guide, Publishers, Bellingham

[20] Olmos Herguedas, F. J.; Sainz Palmero, G.; Cárdenas, C.; San José, S. Análisis y optimización de un sistema productivo mediante simulación discreta, from http://www.cea-ifac.es/ actividades/jornadas/XXI/documentos/ja00_045/ja00_045\%20.pdf, accessed on 22-04-2010 